\title{
Combustion and Exhaust Emissions in a Heavy-Duty Diesel Engine with Increased Premixed Combustion Phase by Means of Injection Retarding
}

\author{
F. Payri ${ }^{1}$, J. Benajes ${ }^{1}$, J. Arrègle ${ }^{1}$ and J.M. Riesco ${ }^{1}$ \\ CMT-Motores Térmicos, Universidad Politécnica de Valencia, Camino de Vera s/n, 46022 Valencia - Spain \\ email: fpayri@mot.upv.es - jbenajes@mot.upv.es - arregle@mot.upv.es - joriav@mot.upv.es
}

\begin{abstract}
Résumé - Processus de combustion et émissions de polluants d'un moteur diesel de poids lourd fonctionnant avec une phase de combustion en prémélange augmentée par retard à l'injection Une étude expérimentale a été réalisée sur un moteur diesel de poids lourd avec des systèmes d'injection et de combustion standard, fonctionnant à faible charge. L'objectif était de promouvoir, en retardant le début de l'injection, une phase de combustion en prémélange importante. Une analyse détaillée des caractéristiques de la combustion obtenues avec un modèle de diagnostic a permis d'étudier les phénomènes basiques à l'origine des variations des prestations et des émissions de polluants du moteur. Une injection de carburant retardée a provoqué de très bas niveaux d'émissions d'oxydes d'azote (NOx) et de suies, avec l'inconvénient d'une augmentation des émissions de monoxyde de carbone (CO) et d'hydrocarbures non ou partiellement brûlés (HC) ainsi qu'une dégradation significative du rendement. En ce qui concerne le fonctionnement de faible charge étudié, la combinaison d'une injection retardée et la recirculation de gaz d'échappement (EGR) s'est avérée très efficace pour réduire les niveaux de suies et de NOx en dessous des futures normes d'émissions, au détriment d'une augmentation de la consommation et des émissions de $\mathrm{CO}$ et d'HC.
\end{abstract}

\begin{abstract}
Combustion and Exhaust Emissions in a Heavy-Duty Diesel Engine with Increased Premixed Combustion Phase by Means of Injection Retarding - An experimental study has been conducted in a HD diesel engine operating at light load with standard injection and combustion systems, retarding the start of injection with the aim of promoting the first phase of combustion in premixed conditions. A detailed study of the combustion characteristics has been carried out by means of a combustion diagnosis model, and the basic phenomena behind the changes in engine performance and pollutant emissions have been studied. Retarded fuel injection has produced very low levels in nitrogen oxides (NOx) and soot emissions, with the inconvenient of higher carbon monoxide (CO) and unburned or partially burned hydrocarbons $(H C)$ emissions and a significant penalty in fuel efficiency. At the light engine load operation point studied here, the combination of retarded fuel injection and the introduction of exhaust gas recirculation (EGR) has proven to be very efficient in achieving soot and NOx levels below the future emission regulations, at the cost of increased fuel consumption and high $\mathrm{CO}$ and $\mathrm{HC}$ emissions.
\end{abstract}




\section{NOTATION}

\begin{tabular}{|c|c|c|}
\hline $\mathrm{A} / \mathrm{F}$ & Air-fuel ratio & \\
\hline aTDC & After top dead center & \\
\hline $\mathrm{BP}$ & Boost pressure & bar \\
\hline bsfc & Brake specific fuel consumption & $\mathrm{g} / \mathrm{kWh}$ \\
\hline cad & Crank angle degree & deg \\
\hline EGR & Exhaust gas recirculation & \\
\hline EP & Exhaust pressure & bar \\
\hline FSN & Filter smoke number & \\
\hline $\mathrm{GCC}$ & Gravity center of combustion & cad \\
\hline HR & Heat release & $\mathrm{kJ}$ \\
\hline HRR & Heat release rate & $\mathrm{kJ} / \mathrm{deg}$ \\
\hline IP & Injection pressure & bar \\
\hline imep & Indicated mean effective pressure & bar \\
\hline iNOx & NOx emission index & $\mathrm{g} / \mathrm{kg}_{\text {fuel }}$ \\
\hline $\mathrm{m}_{\text {fuel }}$ & Injected fuel mass & $\mathrm{mg}$ \\
\hline $\mathrm{PM}$ & Particulate matter & \\
\hline PBF & Premixed-burned fraction & $\%$ \\
\hline PMC & Premixed combustion & \\
\hline sNOx & Specific NOx emission & $\mathrm{g} / \mathrm{kWh}$ \\
\hline SOI & Start of injection & cad aTDC \\
\hline $\mathrm{SOC}$ & Start of combustion & cad aTDC \\
\hline TDC & Top dead center & \\
\hline $\mathrm{T}_{\mathrm{EGR}}$ & Recirculated gas temperature & ${ }^{\circ} \mathrm{C}$ \\
\hline $\mathrm{T}_{\text {in }}$ & Intake temperature & ${ }^{\circ} \mathrm{C}$ \\
\hline$\tau_{\mathrm{id}}$ & Ignition delay time & $\mathrm{ms}$ \\
\hline
\end{tabular}

\section{INTRODUCTION}

The capability of diesel engines to produce efficient power is well known. However, diesel engines exhibit a propensity for high nitrogen oxides (NOx) and particulate matter (PM) emissions. Due to adverse health effects of these pollutants, increasingly stringent emission standards in the world require the simultaneous reduction of PM and NOx emissions from heavy-duty direct-injection diesel engines [1]. Unfortunately, this is a difficult goal because most strategies to reduce either NOx or PM emission cause an increase in the other one. This fact leaves as feasible solution the reduction of one of these pollutants by means of internal measures (adjusting of injection and combustion, swirl and exhaust gas recirculation [2-5]), while the other one is reduced by exhaust gas aftertreatment strategies (like SCR-catalysts for NOx or filters for particulate matter [6-10]).

Compression ignited combustion of premixed, or homogeneous, fuel-air mixture, has recently emerged as a most promising in-cylinder technique to reduce NOx and soot emissions, simultaneously. Some different names have been used to identify this novel combustion process, which include Active Thermo-Atmosphere Combustion (ATAC) [11], Activated Radical (AR) combustion [12], CompressionIgnited Homogeneous Charge (CIHC) [13], HomogeneousCharge Compression-Ignition (HCCI) [14], Premixed Lean
Diesel Combustion (PREDIC) [15], Premixed-Charge Compression Ignition (PCCI) [16], Uniform Bulky combustion System (UNIBUS) [17], Homogeneous charge intelligent Multiple Injection Combustion System (HiMICS) [18], Controlled Autoignition (CAI) [19], Premixed CompressionIgnited (PCI) combustion [20], or Modulated Kinetics (MK) combustion [21]. Aside from some variations between them, all of these methods depend on the low-temperature, distributed reaction of fuel-lean and/or highly diluted mixtures by auto-ignition.

This combustion process has been studied with certain success in two [11, 12] and four stroke engines [13-23], and with liquid [11-23] and gaseous [22, 23] fuels. An additional distinction can be made according to the fuel introduction strategy employed [24]. This distinction include: portinjection $[13,14,16,19,22,23]$, early in-cylinder injection $[15,17,18,20]$, and late in-cylinder injection [21].

At port fuel injection, the fuel is injected into the air upstream of the intake valve, to create a homogeneous charge. The charge is induced into the combustion chamber during the compression stroke, to get auto-ignition close to top dead centre (TDC). The major advantage with these systems is high efficiency (diesel-like) and very low NOx and PM emissions. The major problems are controlling the ignition timing over a wide load and speed range, and high hydrocarbon (HC) and carbon monoxide (CO) emissions.

At early in-cylinder injection, a portion or all of the fuel is injected within the cylinder during the intake stroke or early during the compression stroke. This injection method has been only reported in the literature for diesel fuel, and the fuel injection can be done through separate direct-injectors [15], or through the same nozzles used for diesel combustion $[17,18,20]$. With this method, NOx emissions can be reduced by $90-98 \%$ in comparison to conventional diesel combustion. Soot emissions are very low too. However, $\mathrm{HC}$ and $\mathrm{CO}$ emissions are high and fuel consumption deteriorates. There is not a control on ignition timing, and wall impingement is a problem, too. When ignition occurs, the air-fuel mixture is thought to be nearly homogeneous, with only slight heterogeneity.

The newest approach to this alternative combustion system is the MK concept [21]. In this concept, fuel is injected directly into the combustion chamber near or after TDC, but the ignition delay is extended using large amounts of cooled EGR, a reduction in the engine compression ratio, and vigorous swirl. Despite the significant mixture unhomogeneity that exists in the cylinder, low NOx emissions are obtained. Late in-cylinder injection appears to avoid most of the problems associated with fuel wall impingement and provides some control of the combustion phasing. The short ignition delay of diesel limits this approach to low engine loads.

The purpose of the study reported in this paper was to investigate the potential of the premixed combustion in HD 
diesel engines for meeting future regulations on pollutant emissions. Special attention has been devoted to effects produced by retarded start of fuel injection (SOI) and EGR at low engine load. Tests were performed on a heavy-duty 1.81 single-cylinder engine. The study combines performance and emissions measurements together with heat release law analysis.

\section{OBJECTIVES AND METHODOLOGY}

The particular objective of the project is the investigation of the potential of the premixed combustion (PMC) in HD diesel engines for meeting future pollutant emission regulations. By PMC it is meant the type of combustion produced in a diesel engine when the ignition delay time $\left(\tau_{\text {id }}\right)$ is very large, compared with the injection time. The extreme case would be the conditions when injection occurs completely before the start of combustion. However, intermediate conditions will be also considered as PMC, and included in the scope of the study. The two compatible measures for striving towards complete PMC are shortening the injection duration and increasing the ignition delay.

In order to ensure compatibility with normal injection and combustion conditions, which may be required at other engine operation modes, standard injection hardware has been used in this study, as well as a commercial fuel formulation. Hence, the remaining strategy has been to increase the ignition delay by modifying the in-cylinder gas temperature and pressure during injection by retarding the start of injection. In this instance, when SOI is retarded past top dead center (TDC), gas pressure and temperature during injection start to decrease and $\tau_{\mathrm{id}}$ increases. The focus of the study has been placed on a light-load engine operation mode, since the long injection events at medium and high load make the condition of $\tau_{\text {id }}$ longer than injection time practically impossible to achieve.

Even though the main interest of the study has been to understand the PMC process, an effort has been made to detect the potential in achieving the specific emissions limits of upcoming regulations. In this regard, the retarding of SOI by itself is not able to produce low enough NOx emission levels, and exhaust gas recirculation (EGR) has been included as an additional measure in the study.

From the engine tests, direct information on performance behaviour can be obtained in terms of brake specific fuel consumption (bsfc) and pollutant emissions, mainly NOx and dry soot. Valuable additional information can be extracted from in-cylinder pressure, such as the heat release (HR) and several associated parameters, like combustion duration, burnt temperature, ignition delay, etc.

For this purpose, a combustion diagnosis code CALMEC [25-27] has been used. It is based on the solution of the energy equation inside the cylinder, with the assumption of uniform pressure and temperature over the volume. This single-zone model approach allows calculating the instantaneous average temperature as well as the instantaneous heat released from the burnt fuel. With simple additional hypotheses $[28,29]$, this model can be extended to a two-zone model that provides information on the instantaneous temperature of both the burnt and unburned gas fractions.

The cylinder gas pressure was recorded at 0.2 crank degree intervals and used to compute the auto-ignition delay, the combustion duration, the heat release rate (HRR) and the instantaneous temperature of both burnt and unburned gas fractions.

The start of combustion was defined as the point where the heat release rate turns from negative to zero and the combustion period is defined by the point at which the cumulative heat release curve reaches $90 \%$ of the total value.

\section{EXPERIMENTAL FACILITY AND TEST CONDITIONS}

The engine used in this work is a single-cylinder, four-stroke, direct-injection diesel research engine with 1.81 displacement, well representative of the large truck engines. Detailed basic specifications of the engine are given in Table 1.

TABLE 1

Engine specifications

\begin{tabular}{l|l}
\hline Engine type & $\begin{array}{l}\text { Direct-injection diesel, } 4 \text { stroke-cycle } \\
\text { single cylinder } \\
123 \times 156 \mathrm{~mm}\end{array}$ \\
Bore $\times$ stroke & $1.85 \mathrm{dm}^{3}$ \\
Displacement & 16.3 \\
Compression ratio & Common rail \\
Fuel injection system & Number of holes: 8 \\
Injection nozzle & Hole diameter: $0.178 \mathrm{~mm}$ \\
&
\end{tabular}

The engine was installed in a fully instrumented test cell, with all the auxiliary facilities required for the operation and control of the engine. Figure 1 shows a scheme of the installation.

To provide the intake air conditions as in the real production engine, a screw compressor supplied the required boost pressure, while air temperature at the engine intake was controlled by an external cooler, keeping the desired inlet conditions in a settling chamber upstream of the intake pipe. Intake air flow rate was measured by a hot wire flow meter. The exhaust backpressure produced by the turbine in the real engine was replicated by a valve placed in the exhaust system, controlling the pressure in the exhaust settling chamber.

When EGR needs to be produced, exhaust gas is taken from the exhaust settling chamber, cooled by a gas-water intercooler to the desired temperature, and then introduced into the intake pipe, as shown in Figure 1. The temperature at 


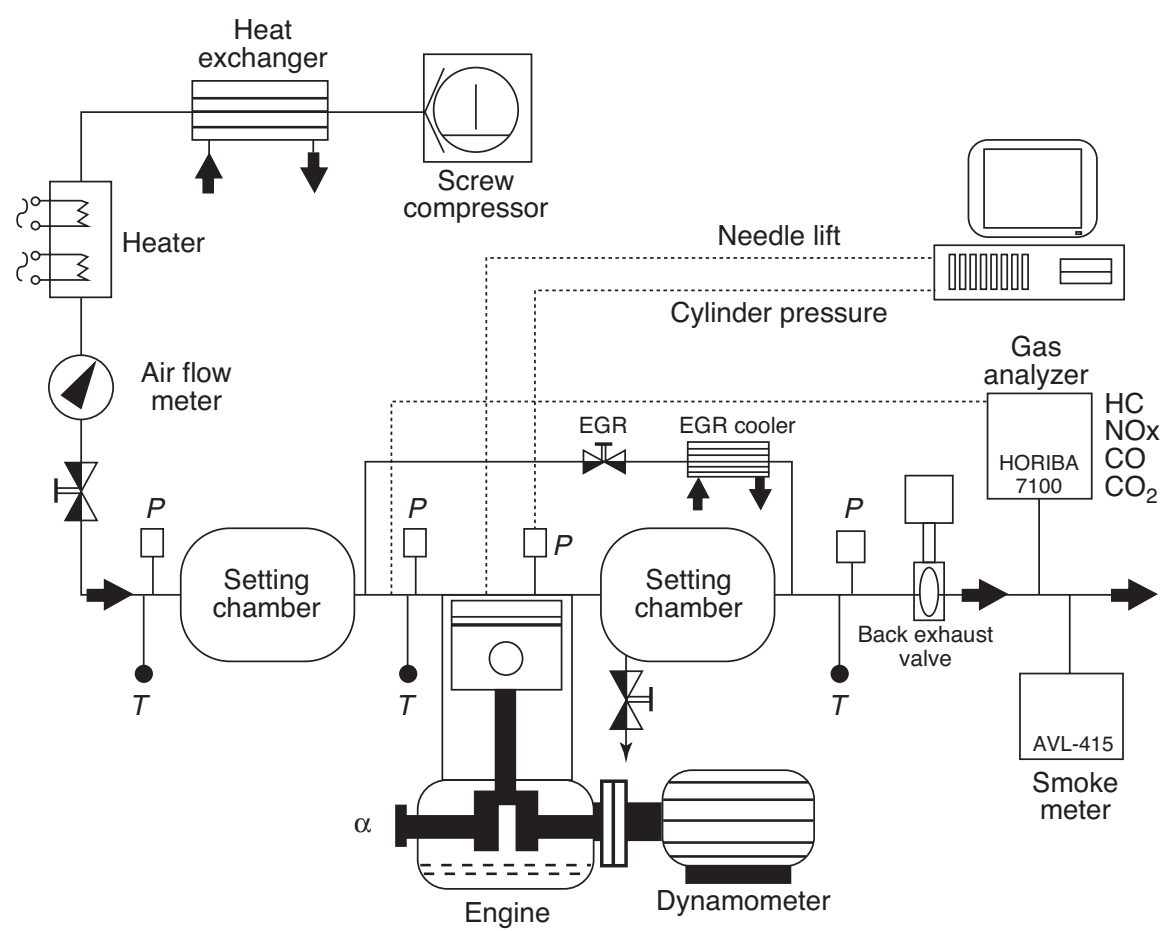

Figure 1

Scheme of the engine test facility.

the EGR settling chamber is controlled electronically and in this study it was kept at a constant value of $80^{\circ} \mathrm{C}$ in all the tests. In order to ensure a large enough EGR mass flow rate, exhaust pressure was maintained 0.01 MPa above the intake pressure in all the operating conditions. The exact EGR rate was controlled by means of a valve between the EGR settling chamber and the intake pipe.

At every engine operating point, the in-cylinder pressure traces from a piezo-electric transducer were recorded during 25 engine cycles in order to compensate for dispersion in engine operation. The filtered average pressure signal was used as input for the combustion diagnostic model. Injector needle lift was recorded by using an eddy current sensor.

The determination of the EGR rate was carried out using the experimental measurement of intake and exhaust $\mathrm{CO}_{2}$ concentration. The concentration of $\mathrm{NOx}, \mathrm{CO}, \mathrm{HC}$, intake and exhaust $\mathrm{CO}_{2}$, and $\mathrm{O}_{2}$ was measured with specific stateof-the-art analysers. Smoke emission was measured with a variable sampling smoke meter, providing results directly in FSN (Filter Smoke Number) units that were transformed into dry soot mass emissions by means of the correlation proposed by Christian et al. [30]. However, in the interpretation of the absolute values of dry soot presented later, one must take into account that, aside from not considering non-visible particulate matter, this correlation was originally obtained for diesel combustion modes with a predominant diffusive phase.
The basic engine operation conditions in the singlecylinder engine are listed in Table 2. EGR was introduced at one selected retarded SOI mode, with very low soot levels, until achieving NOx values in the range of the limits imposed by emission regulations. When EGR was introduced, the temperature of the recirculated gases was controlled in order to achieve a realistic cold-EGR condition of $80^{\circ} \mathrm{C}$. Then, the EGR flow was mixed with the intake flow whose temperature was kept constant at $35^{\circ} \mathrm{C}$, resulting in a higher induced gas temperature.

TABLE 2

Test conditions

\begin{tabular}{|c|c|c|c|c|}
\hline $\begin{array}{l}\text { Unchanged } \\
\text { parameters }\end{array}$ & $\begin{array}{l}\text { SOI cad } \\
\text { aTDC }\end{array}$ & $\begin{array}{c}\text { EGR } \\
(\%)\end{array}$ & $\mathbf{A} / \mathbf{F}$ & $\begin{array}{c}\text { T }_{\text {EGR }} \\
\left({ }^{\circ} \mathrm{C}\right)\end{array}$ \\
\hline \multirow{3}{*}{ Speed $=1500 \mathrm{rpm}$} & -8 & \multirow{7}{*}{0} & \multirow{7}{*}{46} & \multirow{7}{*}{ - } \\
\hline & -6 & & & \\
\hline & -4 & & & \\
\hline \multirow{2}{*}{$\begin{aligned} \mathrm{m}_{\text {fuel }} & =62 \mathrm{mg} \\
\mathrm{T}_{\text {in }} & =35^{\circ} \mathrm{C}\end{aligned}$} & -2 & & & \\
\hline & 0 & & & \\
\hline $\mathrm{BP}=1.50 \mathrm{bar}$ & +2 & & & \\
\hline \multirow{3}{*}{$\begin{array}{l}\mathrm{EP}=1.60 \mathrm{bar} \\
\mathrm{IP}=1200 \mathrm{bar}\end{array}$} & +4 & & & \\
\hline & \multirow{2}{*}{+6} & 30 & 35 & \multirow{2}{*}{80} \\
\hline & & 40 & 31 & \\
\hline
\end{tabular}




\section{RESULTS OF COMBUSTION PROCESS}

\subsection{Global Effect on Combustion}

When SOI is retarded from an advanced timing of SOI -8 ( 8 cad before TDC), the balance between the two phases, premixed combustion and diffusion combustion, changes in favour of the former. This can be observed in Figure 2, where the plots of heat release rate (HRR) are shown for SOI changing from -8 up to +6 cad after TDC. It is evident that the first peak of heat released during the premixed phase increases, especially from $\mathrm{SOI}+0$ on.

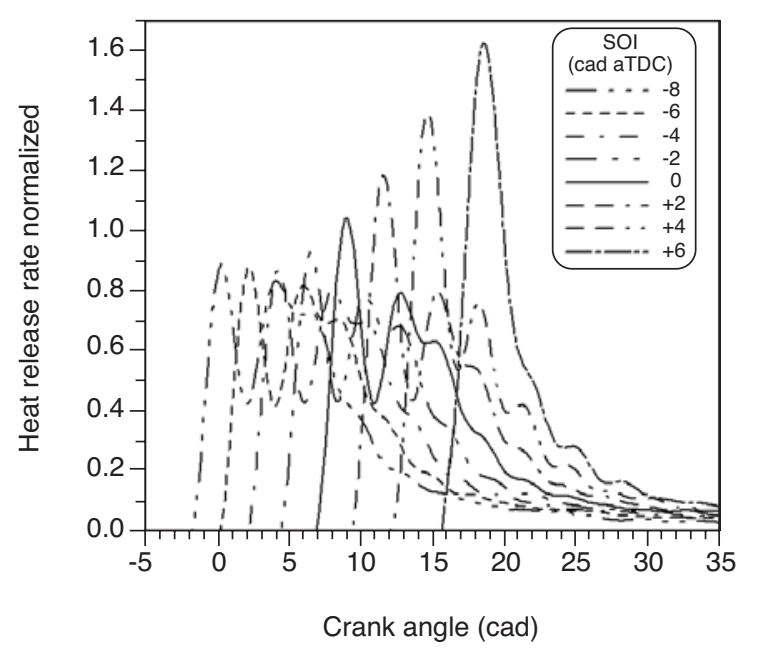

Figure 2

Rate of heat release for different SOI.

When SOI was retarded past 6 cad after TDC, combustion started to deteriorate, and finally, a decline in combustion rate was observed, making engine operation unstable. This limit of SOI +6 was found to be slightly dependent on the particular engine operation conditions, particularly on injection pressure and boost pressure. However, for a safe engine operation, at the given conditions of the study, a most retarded point of SOI +6 was chosen.

A clearer insight into the effect on combustion can be gained from Figure 3, where several parameters are plotted versus SOI. The percentage of fuel mass burned during the premixed combustion phase exhibits a sharp increase at SOI values past TDC, attaining values ranging to $55 \%$ at $\mathrm{SOI}+6$. However, it is evident that the complete premixed combustion has not been achieved at such a retarded SOI, when combustion already starts to deteriorate.

The effect on the total duration of combustion (Fig. 3), shows a constant shortening of the combustion time from SOI -2 . The reason is the larger amount of fuel mass burnt in premixed conditions, with a faster combustion rate than during the subsequent diffusion-controlled combustion process.
The basic reason for these effects is the increase in the auto-ignition delay, when SOI is retarded, as it can be observed in Figure 3 too, where the time elapsed between SOI and SOC is plotted versus SOI. The constant value of injection duration is equal to $1.40 \mathrm{~ms}$, much longer than the ignition delay. This means that combustion starts always before the end of injection, which is coherent with the percentage values of fuel mass burnt in premixed conditions.

As a characteristic value of the in-cylinder temperature during combustion, the maximum value of burnt gases temperature has been plotted versus SOI in Figure 3, where it can be observed that retarding SOI produces a monotonic decrease in this temperature. This behaviour will be related later to the production of NOx emissions.

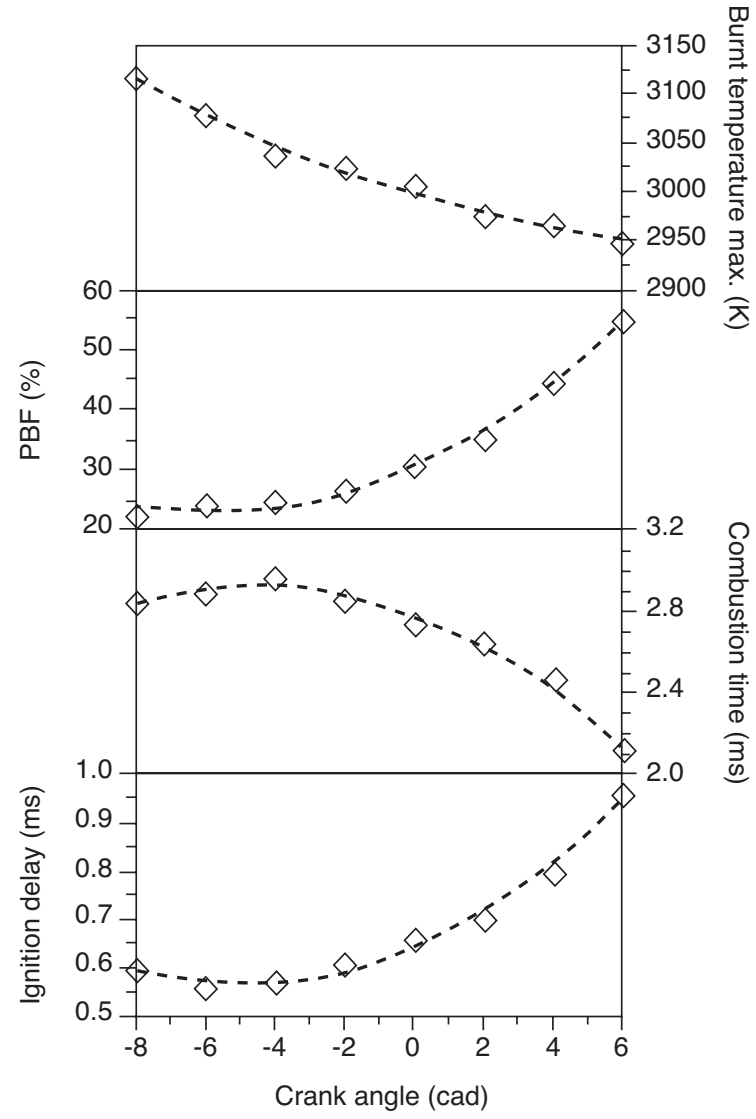

Figure 3

Maximum burnt gas temperature, premixed burned fraction, combustion time and ignition delay.

\subsection{Effect on Engine Performance}

In spite of shortening the overall combustion time, the retarding of SOI produces an unfavourable late release of energy, as it can be seen in Figure 4, which shows the plots of in-cylinder pressure versus crank angle for several values 


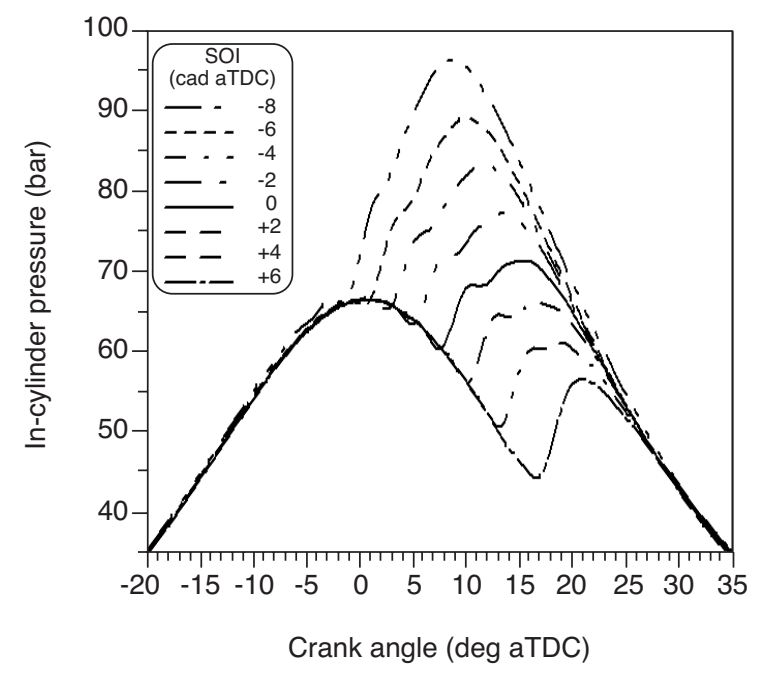

Figure 4

In-cylinder pressure evolution.

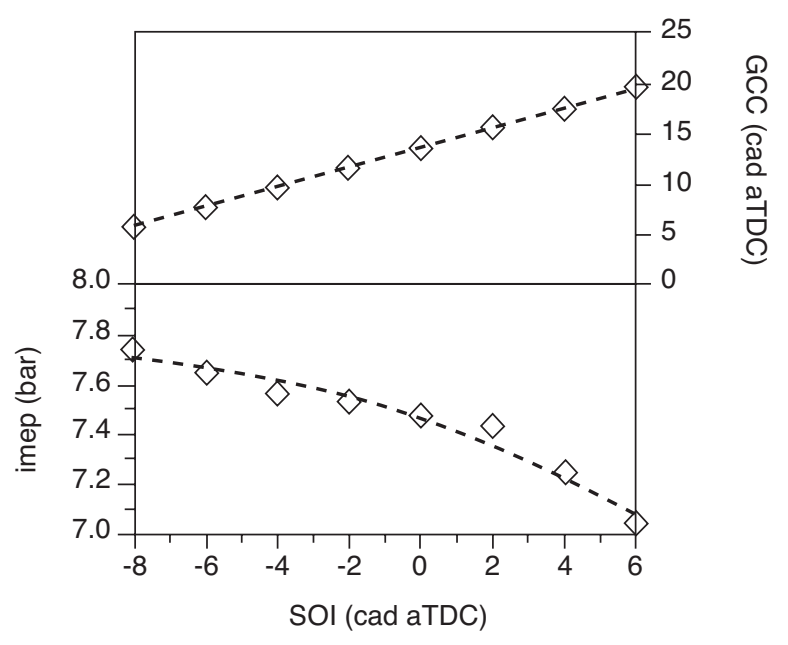

Figure 5

Indicated mean effective pressure (imep), and gravity centre of combustion (GCC).

of SOI. The retarded combustion produces a clear reduction in engine power, which can be evaluated by the value of indicated mean effective pressure (imep) plotted versus SOI in Figure 5. Being the injected fuel mass constant, the variation of the curve is identical to the variation in engine indicated efficiency and similar to the effective fuel consumption.

The main reason for the decrease in imep is the retarding of the combustion process due to the retarding of the SOI, as it can be concluded from Figure 6, which plots the position of the gravity centre of combustion (GCC) that is the crank angle degree where $50 \%$ of the fuel mass has been burned. The effect of this parameter on fuel efficiency is well known, and in spite of the globally faster combustion, the retarding in the position of GCC is responsible for the decrease in imep.

If imep is plotted versus GCC, as in Figure 6, it can be observed how there is a more than linear decay of imep at the most retarded SOI cases. In these cases, one would expect a rapid decay in the heat release rate during the last stages of the diffusion-controlled combustion, due to the fast reduction in in-cylinder gas density.

\subsection{Soot Emissions}

The effect of retarding SOI on soot emissions can be observed in Figure 7. When retarding from a very advanced SOI, the usual increase in soot is observed. However, there is an interesting change in the trend when injection starts around SOI 0 (TDC). From here on, the smoke opacity declines monotonically.

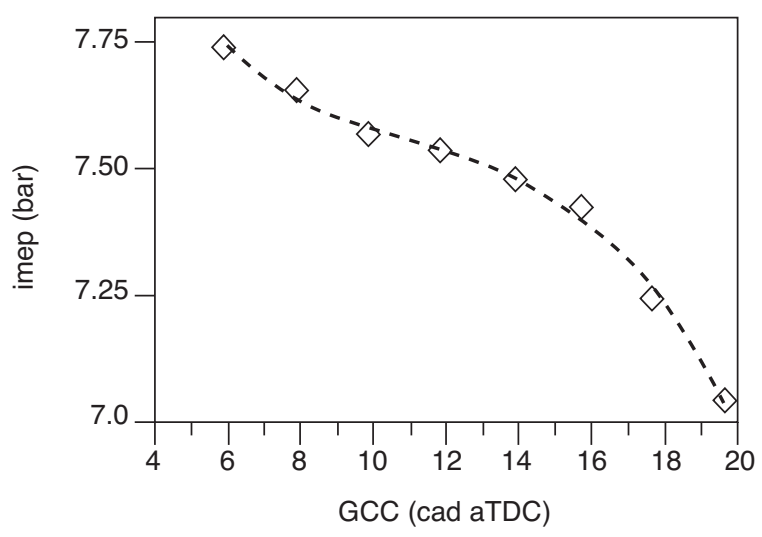

Figure 6

Indicated mean effective pressure (imep) $v s$. GCC.

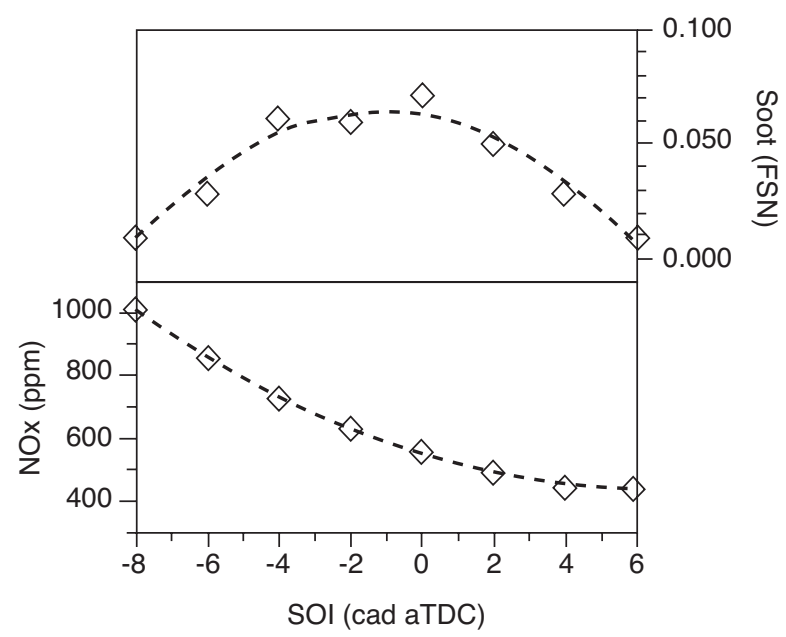

Figure 7

Variation of NOx and soot emissions. 

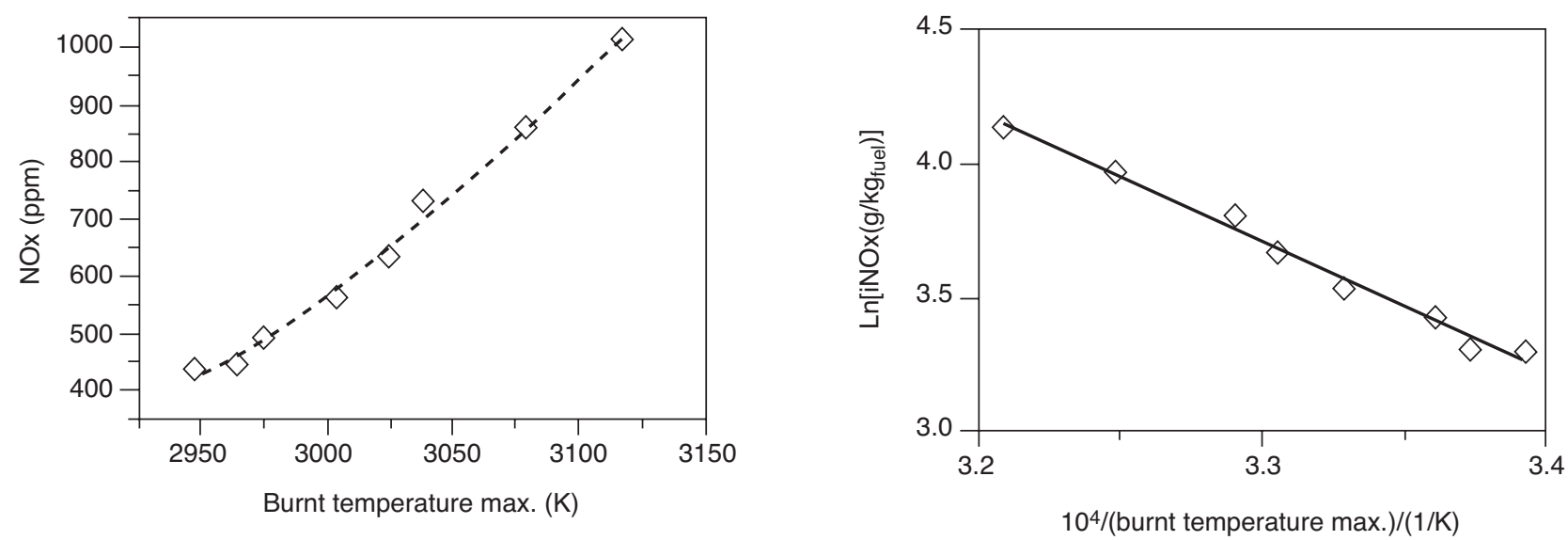

Figure 8

NOx emissions $v s$. burnt gas temperature.

The reason for this second behaviour should be the increase in the ignition delay, which promotes the premixed combustion and consequently reduces the fuel mass burnt in the last phase by diffusion, where soot is mostly formed. During the early stage of combustion, local A/F ratio is very high, and consequently little soot is formed.

\subsection{NOx Emissions}

Figure 7 shows the evolution of NOx emissions versus SOI. Similarly to the case of soot, when SOI is retarded, NOx emissions decrease steadily, as usual, due to the lower incylinder temperatures, commented above (Fig.4). In fact, if NOx emissions are plotted versus maximum temperature, as in Figure 8, a clear monotonic trend is observed. A more general relationship can be obtained if the logarithm of the NOx mass emission per mass of fuel (NOx emission index) is plotted versus the inverse of the maxim burnt gas temperature (Fig. 8).

\section{5 $\mathrm{CO}$ and HC Emissions}

Emissions of CO plotted in Figure 9 remain always at low or moderate values, until SOI 0 , from where they increase steadily. Excessive levels can be attained in the most retarded cases, especially when EGR is introduced, as it will be commented later. Emission of $\mathrm{CO}$ is generally an indication of incomplete oxidation of fuel, and it is very dependent on the combustion temperature. With advanced combustion, very little $\mathrm{CO}$ is generated. However, when combustion is retarded, which happens with retarded SOI, maximum gas temperatures are lower, as is the volume increase during the expansion stroke, and $\mathrm{CO}$ increases drastically.

Figure 9 shows also the variation of $\mathrm{HC}$ emissions with SOI. A similar trend as in the case of $\mathrm{CO}$ can be observed,

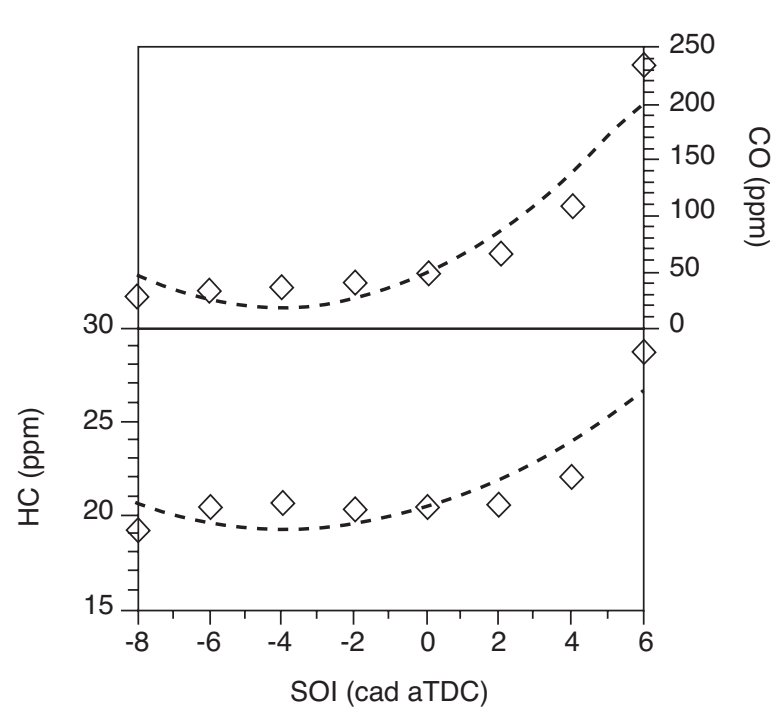

Figure 9

Variation of $\mathrm{HC}$ and $\mathrm{CO}$ emissions.

although the relative increase from advanced SOI cases is smaller. The low combustion temperatures prevent NOx formation, but the combustion temperature becomes too low to fully oxidize the fuel completely. This low combustion temperature results in high emissions of $\mathrm{HC}$ at more retarded SOI, as it is showed in Figure 9.

\subsection{Combustion Noise}

The alteration of the combustion process towards sharper heat release curves, can have a negative effect on the noise level produced by the combustion. A direct estimation of this effect can be gained by calculating the maximum value of the time derivative of the instantaneous in-cylinder pressure. The 
values of this magnitude are plotted in Figure 10 versus the injection timing.

It can be observed how this peak value decreases until SOI at TDC, and then raises in the region of interest past TDC, where the largest pollutant reduction has been observed. However, the maximum values in this region of retarded SOI are similar or even lower than in a normal advanced timing condition.

Another mean of expressing the whole contribution to noise production is by calculating noise intensity in $\mathrm{dB}$, by taking in consideration the whole noise spectra of the incylinder pressure and applying an attenuation function for the engine bloc. This calculation is carried out by the diagnosis model CALMEC commented before, based on the ideas of Anderton [31]. The results of this calculation are plotted in Figure 10.

Even though this calculation method has not been validated experimentally on this particular engine, both type of results in Figure 10 seem to demonstrate that the enhancement of PMC conditions at this engine operation mode does not increase combustion noise to levels higher than those found in plain operating conditions.

\subsection{Dry Soot - NOx Trade Off}

The already commented effects on emissions of soot and NOx can be corroborated in the plots of the trade-offs in Figure 11. As usual, emission levels have been plotted in specific values (mass flow rate divided by engine power), which makes the figures dependent on the variation of engine power commented above. Three phases in the trade-off can be distinguished.
First, retarding SOI until TDC, the usual trend of increasing soot and decreasing NOx is observed. When injection timing is further retarded until SOI +4 a sharp decrease in soot happens, while NOx continue the usual decrease. Finally, at SOI +6 , NOx emissions increase again, mainly due to the reduction in engine power, while soot follows the declining trend started earlier.

The outcome is a curious hook-like curve, with a very important relative reduction in NOx emission, but with absolute values very far from the objectives of emission regulations. Dry soot levels are kept by this strategy at the very low initial values corresponding to advanced injection timing.

\section{8 bsfc-NOx Trade-Off}

Figure 11 shows also the bsfc-NOx trade-off, where, the commented monotonic increase in bsfc yields also a hooklike curve. Maximum bsfc values range is about $15 \%$ higher than with the most advanced SOI. This outcome is perhaps the worst aftermath of the strategy of retarding SOI.

\section{RESULTS WITH INTRODUCTION OF EGR}

Given the relatively high NOx and low soot emissions levels obtained with retarding SOI, which are far from the objectives of future emission restrictions, and in order to evaluate the potential of PMC in tolerating EGR, this strategy was tested at a selected SOI +6 (6 cad after TDC). Two values of EGR rates of 30 and $40 \%$ were produced, as shown previously in Table 2 .

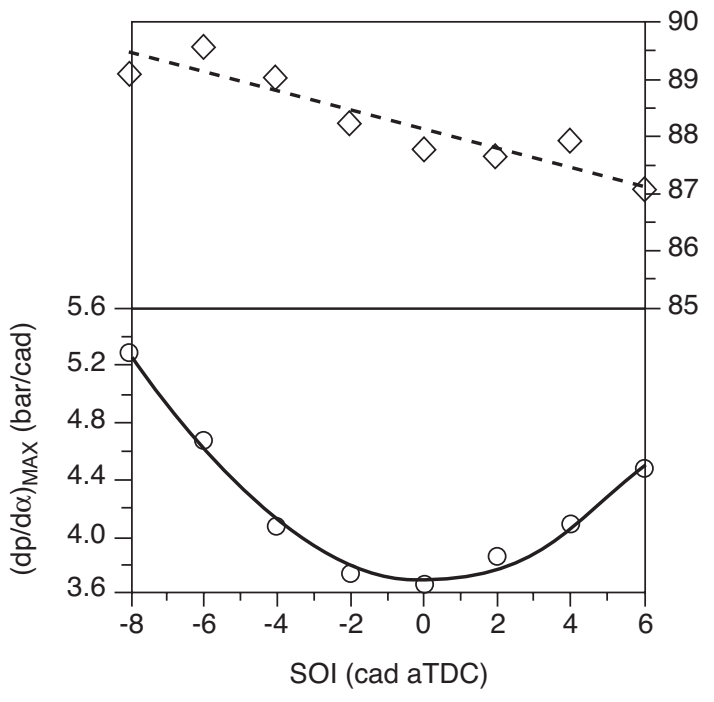

Figure 10

Calculated combustion noise level and pressure variation.

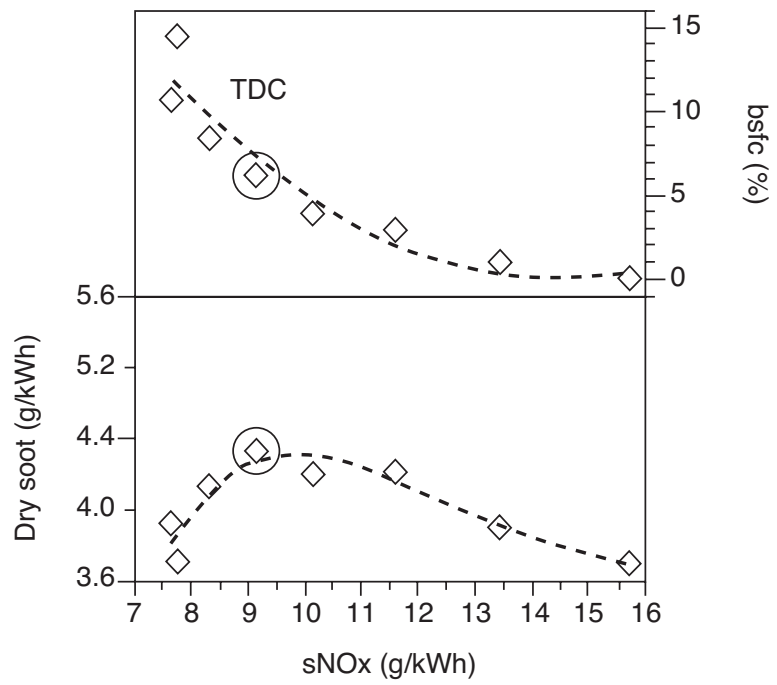

Figure 11

Dry soot-sNOx and bsfc-sNOx trade-offs. 


\subsection{Combustion Process}

Among the well-known effects of EGR on the combustion process [32-34], the thermal and dilution factors are expected to cause a slow down of the basic oxidation processes. This condition affects the ignition delay and the overall combustion duration, which become longer as it can be corroborated in the plots of Figure 12, where the rate of heat release and

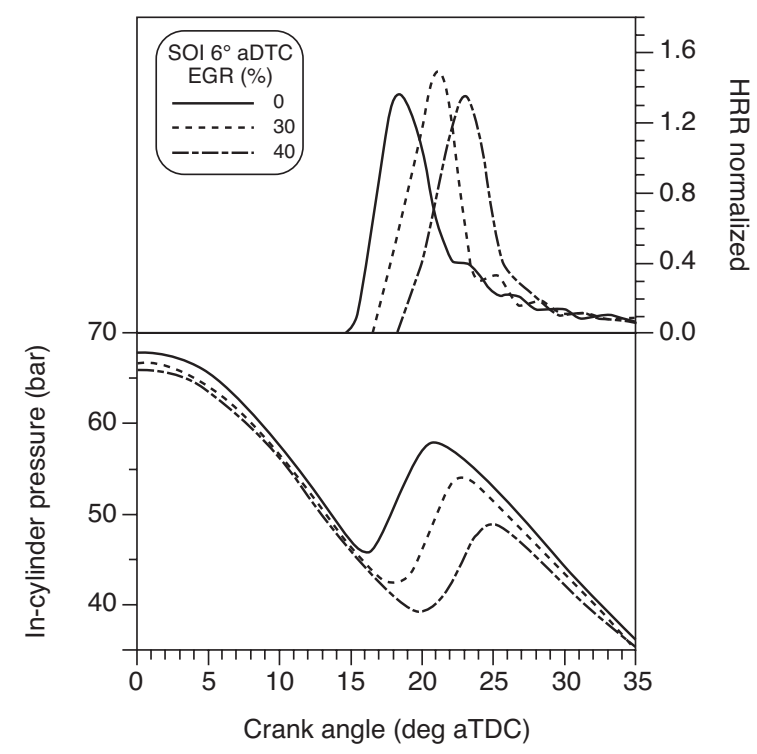

Figure 12

In-cylinder pressure evolution and normalized HRR.

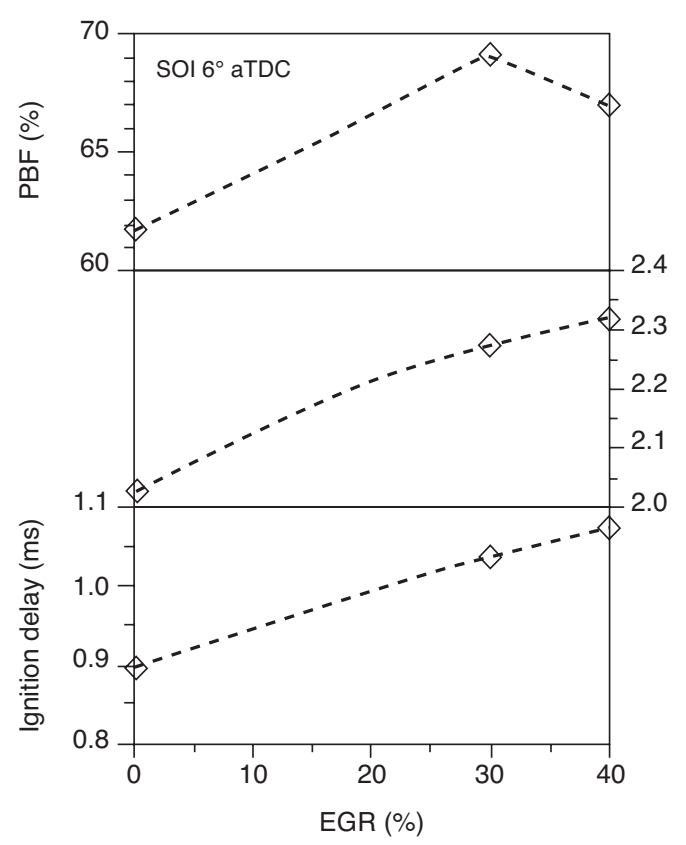

Figure 13

Premixed burned fraction, combustion time and ignition delay. the in-cylinder pressure evolution has been plotted for the different EGR conditions. These effects have been quantified in Figure 13 depicting the influence of the percentage in EGR on the variations of combustion duration and the ignition delay. Because of the extension of the ignition delay, the percentage of fuel mass burnt in PMC conditions increases, too, as shown in Figure 13. This phenomenon might be responsible for the less than expected increase in soot emissions with EGR rate that will be showed later.

\subsection{Engine Performance}

The slow-down of the heat release process reduces engine performance and thus reduces imep as it can be corroborated in Figure 14. In additional tests, it was observed that the relative reduction in imep from the starting level without EGR could be very different depending on SOI. In general, a

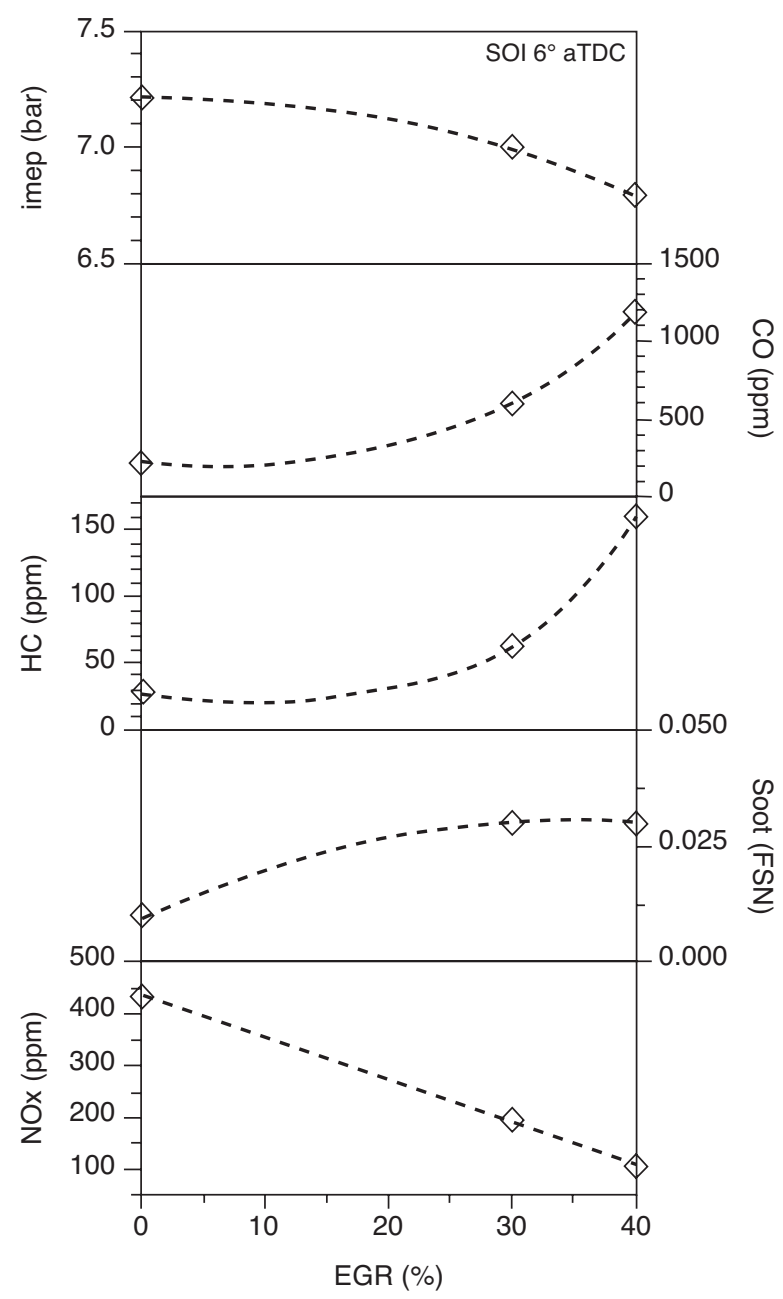

Figure 14

Variation of imep, NOx, soot emissions, $\mathrm{HC}$ and $\mathrm{CO}$ emissions with EGR rate. 
common result is that worsening of imep is more influenced by EGR when SOI is more retarded.

\subsection{NOx Emissions}

EGR produces always the desired effect of NOx reduction. This phenomenon has been assessed as being general among all the tested points, and an almost constant relationship has been observed between the relative reduction in NOx and the percentage of EGR introduced. This reduction is depicted in the plot of Figure 14

\subsection{Soot Emissions}

The main negative consequence of EGR is the well-known increase in soot emission. For this reason, EGR has been proven efficient in attaining the emission targets only when the starting value of soot without EGR was low enough. In addition, a very different sensibility to the increase in soot by EGR has been observed, depending on SOI. Indeed, the more retarded SOI is, the less sensible soot emission are to EGR. This effect can be corroborated in the case of most retarded SOI presented in Figure 14, where it can be observed that FSN remains at very low values in spite of an EGR rate of $40 \%$.

\section{5 $\mathrm{CO}$ and HC Emissions}

As observed in Figure 14, the introduction of EGR has an important negative effect on the emissions of $\mathrm{HC}$ and $\mathrm{CO}$, which adds up to the initial increase produced by the retarded SOI. The introduction of $40 \%$ EGR multiplies by four the initial emission of both pollutants.

\subsection{Soot - NOx Trade Off}

From the already commented results, and from the plots in Figure 15 it can be stated that EGR is efficient for reducing the NOx emissions to very low values, in the range of future pollutant emission restrictions. The good tolerance to EGR at such retarded SOI allows complying with the low limits in dry soot. Indeed, at sNOx values below $1.5 \mathrm{~g} / \mathrm{KWh}$, extreme low specific dry soot levels of less than $0.003 \mathrm{~g} / \mathrm{KWh}$ were recorded, which is far below the global limits of future European standards Euro IV and Euro V.

In the appraisal of these good results, two circumstances should be taken into account. On one hand, the results presented here correspond to just only one of the 13 modes in the European Stationary Cycle for heavy-duty Diesel engines. On the other hand, the dry soot results plotted here have been calculated from smoke opacity measurements, applying a certain correlation, as commented above. It can be expected that at light engine load, total particulate matter

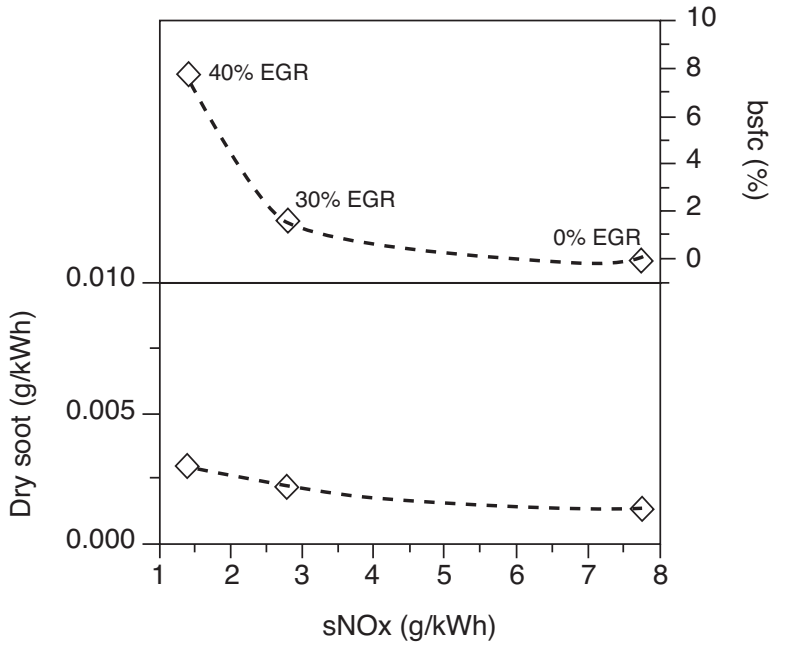

Figure 15

Dry soot-sNOx and bsfc-sNOx trade-offs.

emissions could be as high as twice the dry soot values presented here.

\section{7 bsfc-NOx Trade-Off}

EGR is known to produce a general increase in bsfc. However, in the case of most retarded SOI presented in Figure 15, a $40 \%$ EGR rate is responsible for an increase of about $8 \%$ in bsfc. Nevertheless, the main disadvantage of this combustion mode is the already high bsfc values attained without EGR when SOI is so much retarded.

\section{CONCLUSIONS}

From the study carried out in a HD diesel engine at a light load engine operating mode, retarding SOI until past TDC, the following main conclusions have been obtained.

Ignition delay was extended significantly by SOI retard, but it was not possible to achieve a complete premixed combustion, and only $55 \%$ of the injected fuel mass was burnt in these conditions at the most retarded SOI. Introducing EGR, this figure was extended up to about $70 \%$.

The prolongation of the auto-ignition delay promoted the premixed combustion phase, with the following main effects:

- shorter overall combustion process, with lower combustion temperature;

- reduction in the fuel mass burnt in the diffusion-controlled phase;

- important and constant reduction in NOx emissions;

- very low dry soot emissions at the most retarded SOI modes;

- important and monotonic increase in bsfc and in emissions of $\mathrm{HC}$ and $\mathrm{CO}$. 
In order to reduce further NOx emissions below the limits of future regulations, EGR was introduced at the most retarded SOI. The main conclusions obtained with this strategy are:

- retarded SOI modes are very tolerant to EGR, and the increase in dry soot emissions due to EGR was very low, in spite of EGR rates in the range of $40 \%$;

- a huge increase in $\mathrm{CO}$ and $\mathrm{HC}$ emissions was produced;

- a small increase of bsfc of about $8 \%$ was produced by EGR rates of $40 \%$.

In general, it can be concluded that the strategy of retarding SOI combined with high EGR rates is convenient at light engine load for reducing NOx and dry soot emissions, at the cost of a significant increase in fuel consumption and in emissions of $\mathrm{CO}$ and $\mathrm{HC}$.

\section{ACKNOWLEDGEMENTS}

The authors want to thank to Renault Trucks for the technical and economical support in this study.

\section{REFERENCES}

1 Moser, F.X., Sams, T. and Cartellieri, W. (2001) Impact of Future Exhaust Gas Emission Legislation on the Heavy Duty Truck Engine. SAE Paper 2001-01-0186.

2 Payri, F., Benajes, J., Molina, S. and Riesco, J.M. (2003) Reduction of Pollutant Emissions in a HD Diesel Engine by Adjustment of Injection Parameters, Boost Pressure and EGR. SAE Paper 2003-01-0343.

3 Pierpont, D.A., Montgomery, D.T. and Reitz, R.D. (1995) Reducing Particulate and NOx Using Multiple Injections and EGR in a D.I. Diesel. SAE Paper 950217.

4 Herzog, P.L., Bürgler, L., Winklhofer, E., Zelenka, P. and Cartellieri, W. (1992) NOx Reduction Strategies for DI Diesel Engines. SAE Paper 920470.

5 Benajes, J., Molina, S., García, J.M. and Riesco, J.M. (2004) The Effect of Swirl on Combustion and Exhaust Emissions in Heavy-Duty Diesel Engines. Proc. Instn. Mech. Engrs. Part D: J. Automobile Engineering, 218, 1141-1148.

6 Johnson, T.V. (2001) Diesel Emission Control in Review. SAE Paper 2001-01-0184.

7 Miller, W.R., Klein, J.T., Mueller, R., Doelling, W. and Zuerbig, J. (2000) The Development of Urea-SCR Technology for US Heavy Duty Trucks. SAE Paper 2000-01-0190.

8 Allansson, R., Cooper, B.J., Thoss, J.E., Uusimäki, A., Walker, A.P. and Warren, J.P. (2000) European Experience of High Mileage Durability of Continuously Regenerating Diesel Particulate Filter Technology. SAE Paper 2000-010480 .

9 Romero, A.F. (1992) Self Regenerating Particulate Matter System for on and off-Highway Diesel Engines. SAE Paper 921674.

10 Stratakis, G.A., Psarianos, D.L. and Stamatelos, A.M. (2003) Experimental Investigation of the Pressure Drop in Porous Ceramic Diesel Particulate Filters. Proc. Instn. Mech. Engrs. Part D: J. Automobile Engineering, 217, 307-317.

11 Onishi, S., Jo, S.H., Shoda, K., Jo, D.P. and Kato, S. (1979) Active Termo-Atmosphere Combustion (ATAC) - A New
Combustion Process for Internal Combustion Engines. SAE Paper 790501.

12 Ishibashi, Y. and Asai, M. (1996) Improving the Exhaust Emissions of Two-Stroke Engines by Applying the Activated Radical Combustion. SAE Paper 960742.

13 Najt, P.M. and Foster, D.E. (1983) Compression-Ignited Homogeneous Charge Combustion. SAE Paper 830264.

14 Thring, R.H. (1989) Homogeneous-Charge CompressionIgnition (HCCI) Engine. SAE Paper 892068.

15 Takeda, Y., Keiichi, Na. and Keiichi, Ni. (1996) Emission Characteristics of Premixed Lean Diesel Combustion with Extremely Early Staged Fuel Injection. SAE Paper 961163.

16 Aoyama, T., Hattori, Y., Mizuta, J. and Sato, Y. (1996) An Experimental Study on Premixed-Charge Compression Ignition Gasoline Engine. SAE Paper 960081.

17 Yanagihara, H.A. (1996) A Simultaneous Reduction of NOx and Soot in Diesel Engines Under a New Combustion System (uniform bulky combustion system UNIBUS). 17th. Int. Motor Symposium, Vienna.

18 Yokota, H., Kudo, Y., Nakajima, H., Kakegawa, T. and Susuki, T. (1997) A New Concept for Low Emission Diesel Combustion. SAE Paper 970891.

19 Lavy, J. et al. (2000) Innovative Ultra-Low NOx Controlled Auto-Ignition Combustion Process for Gasoline Engines: the 4-SAPACE Project. SAE Paper 2000-01-1837.

20 Iwabuchi, Y., Kawai, K., Shoji, T. and Takeda, Y. (1999) Trial of New Concept Diesel Combustion System-Premixed Compression-Ignited Combustion. SAE Paper 1999-01-0185.

21 Kimura, S., Aoki, O., Ogawa, H., Muranaka, S. and Enomoto, Y. (1999) New Combustion Concept for Ultra-Clean and High-Efficiency Small DI Diesel Engines. SAE Paper 199901-3681.

22 Christensen, M., Johansson, B. and Einewall, P. (1997) Homogeneous Charge Compression Ignition (HCCI) Using Isooctane, Ethanol and Natural Gas - A Comparison with Spark-Ignition Operation. SAE Paper 972874.

23 Christensen, M., Johansson, B., Amnjus, P. and Mauss, F. (1998) Supercharged Homogeneous Charge Compression Ignition. SAE Paper 980787.

24 Stanglmaier, R.H., Ryan III, T.W. and Mehta, D. (2001) Fuel Introduction Strategies for Pre-Mixed Compression-Ignition combustion. In: A New Generation of Engine Combustion Processes for the Future? P. Duret (Ed.), Editions Technip, Paris.

25 Armas, O. (1998) Experimental Diagnostic of Combustion Process in Direct Injection Diesel Engines (in Spanish). $P h D$ Thesis, Universidad Politécnica de Valencia, Spain.

26 Lapuerta, M., Armas, O. and Hernández, J.J. (1999) Diagnostic of D.I. Diesel Combustion from In-Cylinder Pressure Signal by Estimation of Mean Thermodynamic Properties of the Gas. Applied Thermal Engineering, 5, 513-519.

27 Lapuerta, M., Armas, O. and Bermúdez V. (2000) Sensitivity of Diesel Engine Thermodynamic Cycle Calculation to Measurement Errors and Estimated parameters. Applied Thermal Engineering, 20, 9,843-861.

28 Ishida, M., Ueki, H., Matsumura, N., Yamaguchi, M. and Luo G.F. (1996) Diesel Combustion Analysis Based on Two Zone Model (comparison between model analysis and experiment). JSME Int. Journal, Series B, 39, 1, 185-192.

29 García, J., Gil, A. and Estellés, V. (2000) Theoretical and Experimental Model for the Burnt Products of Combustion Temperature Calculating on Direct Injection Diesel Engines" (in Spanish). Anales de Ingeniería Mecánica, 13, 2, 20232028. 
30 Christian, R., Knopf, F., Jasmek, A. and Schindler W. (1993) A New Method for the Filter Smoke Number Measurement with Improved Sensitivity (in German). MTZ, 54,16-22.

31 Anderton, D. (1979) Relation between Combustion System and Noise. SAE Paper 790270.

32 Ladommatos, N., Abdelhaim, S.M., Zhao, H. and Hu, Z. (1998) The Effects of Carbon Dioxide in Exhaust Gas Recirculation on Diesel Engine Emission. Proc. Instn. Mech. Engrs. Part D: J. Automobile Engineering, 212, 25-42.
33 Ladommatos, N., Abdelhaim, S.M. and Zhao, H. (1998) Effects of Exhaust Gas Recirculation Temperature on Diesel Engine Combustion and Emissions. Proc. Instn. Mech. Engrs. Part D: J. Automobile Engineering, 212, 479-500.

34 Ladommatos, N., Abdelhaim, S.M. and Zhao, H. (2000) The Effects of Exhaust Gas Recirculation on Diesel Combustion and Emissions. Int. J. Engine Research, 1, 1, 107-126, 2000.

Final manuscript received in April 2005 